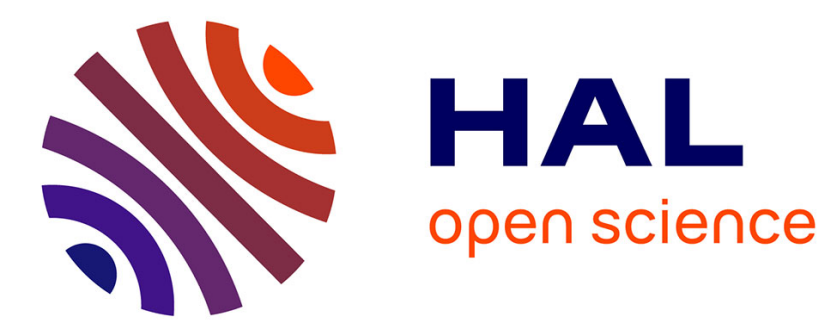

\title{
Beyond Jeannerod's motor simulation theory: An approach for improving post-traumatic motor rehabilitation
}

\author{
Claire Calmels
}

\section{- To cite this version:}

Claire Calmels. Beyond Jeannerod's motor simulation theory: An approach for improving posttraumatic motor rehabilitation. Neurophysiologie Clinique $=$ Clinical Neurophysiology, 2019, 10.1016/j.neucli.2019.01.033 . hal-02051088

\section{HAL Id: hal-02051088 \\ https://hal-insep.archives-ouvertes.fr/hal-02051088}

Submitted on 27 Feb 2019

HAL is a multi-disciplinary open access archive for the deposit and dissemination of scientific research documents, whether they are published or not. The documents may come from teaching and research institutions in France or abroad, or from public or private research centers.
L'archive ouverte pluridisciplinaire HAL, est destinée au dépôt et à la diffusion de documents scientifiques de niveau recherche, publiés ou non, émanant des établissements d'enseignement et de recherche français ou étrangers, des laboratoires publics ou privés. 


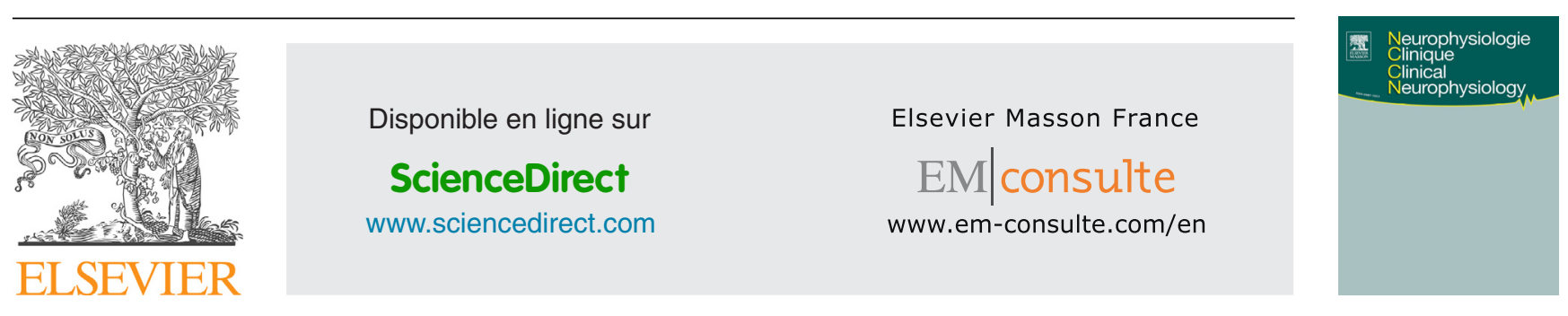

PERSONAL VIEW

\title{
Beyond Jeannerod's motor simulation theory: An approach for improving post-traumatic motor rehabilitation
}

\section{Claire Calmels*}

\author{
Laboratory Sport, Expertise and Performance (EA 7370), Research Department, French Institute of Sport \\ (INSEP), 75012 Paris, France
}

Received 8 September 2018; accepted 12 January 2019

\author{
KEYWORDS \\ Motor simulation; \\ Orthopedic trauma \\ injuries; \\ Recovery; \\ Transient \\ immobilization; \\ Transient \\ sensorimotor \\ deprivation
}

\begin{abstract}
Summary This paper depicts an approach aiming to allow individuals with orthopedic trauma injuries to optimize recovery and safely return to daily life. The core of this approach is motor simulation, used in complement to conventional physical rehabilitation methods. This paper provides recent scientific insights on the basis of motor simulation, discusses benefits of this approach in motor rehabilitation, and provides applied perspectives.

(c) 2019 Elsevier Masson SAS. All rights reserved.
\end{abstract}

\section{Introduction}

This paper describes an approach aimed at allowing individuals with orthopedic trauma injuries to optimize physical recovery and safely return to daily life. The core of this approach is motor simulation, used in complement to traditional physical rehabilitation. According to Jeannerod [47-49], motor simulation is characterized by action-

\footnotetext{
* Laboratoire SEP (EA 7370), unité recherche, institut national du sport, de l'expertise et de la performance, 11, avenue du Tremblay, 75012 Paris, France.

E-mail address: claire.calmels@insep.fr
}

related cognitive states, such as motor imagery or action observation, which activate cortical motor systems similar to those involved during actual action. Motor imagery relies on representational neural networks involving topdown sensorial, perceptual and affective characteristics that are primarily under the conscious control of the imager and which may occur in the absence of perceptual afference, being functionally equivalent to actual motor action experience. On the other hand, action observation relies on representational neural networks involving bottom-up sensorial, perceptual and affective characteristics that are primarily under the subconscious control of the observer and which occur in the presence of afference, also being functionally equivalent to actual motor action experience 
$[41,42]$. Based on Jeannerod's theory [47-49], motor simulation may occur in 3 forms:

- when the action is imaged (imaged action);

- when the action is observed (observed action) or;

- when it is verbally described, either silently or aloud (verbalized action).

This paper is composed of four parts. The first part presents Jeannerod's motor simulation theory on which the aforementioned approach is based. The second part focuses on recent scientific findings on effects of sensory and motor deprivation on motor performance and human brain organization. The third part discusses motor simulation training to counteract detrimental effects of transient sensorimotor deprivation, and the last part suggests applied perspectives.

\section{Motor simulation}

\section{Jeannerod's theory}

This theory explains how motor-related cognitive tasks such as motor imagery (imaging the execution of an action without physically performing it) or action observation (observing an action executed by another or by oneself) are connected to action tasks that are actually performed. The basis of the motor simulation theory is that common cortical motor systems are activated when imaging, observing or executing an action. Jeannerod states that an intended action that is executed consists of two parts: a covert stage, which is not directly observable and an overt stage, which is directly observable [47-49]. The covert stage is a representation of the future: the goal of the action, the means of performing the action and its consequences on the organism and the external world. For the overt stage, this represents the actual action, that is, an action willingly completed. Jeannerod also specified that covert stages could comprise different kinds of action, such as voluntary action that will be subsequently executed (i.e., that will lead to overt action), imagined action or observed action (i.e., covert or simulated action) [47-49]. Therefore, covert and overt actions can be placed on a continuum going from intention to motor execution. Consequently, in order to be generated, an overt executed action must be preceded by a covert stage, whereas a covert action does not necessarily evolve into an overt action. Indeed, when imaging or observing an action, motor command inhibitory mechanisms block motor output. In other words, "covert actions are in fact actions, except for the fact they are not executed" [48]. Jeannerod also advances that covert and overt actions are both preceded by representation of their sensorial consequences and future states. Thus, simulating an action involves a representation of its current state as well as a representation of its subsequent states.

\section{Functional equivalence of imaged/observed action and executed action}

Over the past twenty years, neuroimaging technological developments and widespread use of meta-analyses have allowed some support for Jeannerod's motor simulation theory, showing that both movement simulation (i.e. imaged and observed actions), and actual execution of movement, activate common cortical areas [15,32,36,39,48]. Early neuroimaging literature reviews revealed common recruited motor areas (primary motor and premotor areas, prefrontal and parietal areas, basal ganglia and cerebellum). However, these studies were based on methodology that did not integrate principled statistical testing $[32,48]$. A decade later, Casper et al. [15] and Hetu et al. [39] conducted meta-analyses allowing more objective assessment of the evidence, by independently investigating neural networks involved during motor imagery and action observation i.e. without comparing them to each other and to motor execution.

Very recently, in their meta-analysis, Hardwick et al. [36] examined neural networks involved in action execution, motor imagery and action observation. Using a conjunction analysis across the overt action (i.e., executed action) and its two covert counterparts (i.e., imaged and observed actions), they pinpointed a consistently common premotorparietal and primary somatosensory network. They also identified specific areas for each of these three different tasks. More specifically, a network including premotor, sensorimotor and subcortical structures (putamen, thalamus, and cerebellum) showed activity when subjects performed an actual action, and on the other hand a network involving premotor, parietal and subcortical structures (putamen and cerebellum) was activated when subjects were instructed to imagine an action. When an action was observed, the network involved premotor, parietal and occipital areas with no consistent involvement of subcortical areas.

Taken together Hardwick's team results are broadly in accordance with those of Grezes and Decety [32] and Jeannerod [48] in showing the involvement of premotor and inferior parietal areas when imaging, observing and executing an action. Moreover, Hardwick et al. [36] additionally revealed recruitment of primary somatosensory cortex across these three tasks.

Interestingly, ventral premotor cortex (vPM), dorsal premotor cortex (dPM) and pre-SMA, all areas recruited in motor simulation and execution, are recognized to be involved in action preparation [44] and in learning arbitrary visuomotor mapping $[62,77]$. The VPM cortex is thought to be involved in fine motor coordination [21] whereas its counterpart, the dPM cortex, is presumed to be involved in action selection and to a lesser extent in action execution [69]. The pre-SMA plays a key role in self-initiated actions [40]. Furthermore, it is of interest that inferior parietal cortex is typically implicated in processing multisensory information [7], preparing movement and generating motor intention $[22,23,73]$, as well as in storing kinesthetic representations to map them onto the premotor and motor areas [70]. As previously thought, the primary somatosensory cortex is not limited to processing somatosensory information such as auditory, visual, tactile, proprioceptive and nociceptive information, but rather participates in integrating, transmitting and receiving multimodal information through cortico-subcortical networks, thus regulating sensations and movements in order to make them as effective as possible. This is completed in collaboration with the motor cortex $[8]$. 


\section{Functional equivalence of verbalized action and executed/simulated/mimed action}

Various studies have also demonstrated neuronal network equivalence between verbalized and executed actions. For example, Hauk et al. [37] showed cortical overlap when action verbs related to arm or leg movements were passively read out, and when they were actually executed: in both cases, premotor and primary motor cortices were somatotopically activated. Interestingly, these cortices are recognized to be involved in action programming [44,64,69] and more specifically, primary motor cortex appears to be in charge of encoding levels of muscle activation as well as movement direction.

It has also been evidenced that verbalized action shares functional cortical networks with both simulated action (imaged action or observed action) and mimed action. Firstly, Aziz-Zadeh et al. [2] showed that the (left) premotor area was involved when reading action phrases related to arm or leg movements, as well as when observing them. Secondly, Peran et al. [68] considered three tasks: action verb generation, imaged action, and mimed action. Using fMRI conjunction analysis across these tasks, they revealed common neuronal networks including premotor, parietal, and occipital cortices.

\section{Brain plasticity and transient sensorimotor deprivation}

Development of neuroimaging techniques over the last few years has provided compelling evidence of the brain's ability to reorganize its neuronal connections in form and function throughout life [25], in response to internal and external constraints or goals. This process involves short-term changes which lead to more stable, longer-term alterations, provided that the individual is exposed for a long enough period of time to these constraints or goals, whether internal or environmental [66]. This reconfiguration, known as brain plasticity and driven by sensory input [26,52] and motor output $[16,17,38]$, aims at maximizing the functioning of neural networks during (human) development, during learning, and in response to brain lesions [66]. Generally, brain plasticity is perceived as being beneficial but may also be damaging. When plasticity allows an individual to improve behavioral capacity $[18,24,71]$, it is qualified as adaptive; conversely, when linked to behavioral deterioration and leading to negative consequences, it is seen as maladaptive $[27,28]$.

Effects of sensory and motor deprivation on motor performance and human brain organization have been investigated over recent decades [30]. Some research groups have focused on impairments resulting from neurological injuries (e.g. strokes, limb amputations, spinal cord injuries), whilst others have investigated alterations resulting from orthopedic trauma injuries (e.g. bone fractures, ligament or muscle injury, joint dislocations). In this paper, we consider only orthopedic trauma requiring transient immobilizations of various durations.

\section{Transient sensorimotor deprivation affects motor and cognitive performance}

To examine the effects of transient sensorimotor deprivation on motor or cognitive performance, a short-term upper limb immobilization paradigm in healthy participants has most often been used [3,5,58,60,74].

After immobilizing subjects' left arms for 12 hours, Moisello et al. [60] showed changes in limb kinematics during reaching movements. Changes were not seen after 6 hours of immobilization but occurred after 12 hours, at which time greater hand-path areas and inter-joint coordination timing were observed. Bassolino et al. [3], using a 10-hour immobilization period of the right hand, showed alterations in a reaching-to-grasp task. Increased duration of the reaching phase associated with a time reduction to attain the peak velocity within this phase occurred; the authors interpreted this as reflecting incorrect prediction of sensory consequences of the reaching task. During the immobilization period, since no movement can be performed, no visual or proprioceptive information associated with arm movement is generated. Because this information is essential in order to access and maintain motor representations stored in brain $[9,50]$, the reaching move can no longer be updated. Consequently, discrepancy between expected and actual sensory consequences of the motor command could explain the immobilization-induced changes observed during the execution of the move. Bosbach et al. [9] also stated that in the absence of such peripheral information, motor representations are supposed to fade; consequently, being deprived of such sensations prevents individuals from being able to simulate actions. Ten years later, these findings were supported by Toussaint's research group. This group investigated effects of 48-hour left-hand immobilization in healthy participants on sensorimotor representations $[57,58,74]$. They used hand and foot laterality tasks to determine the quality of sensorimotor representations, as these tasks require implicit use of motor imagery and thus provide information on the central processing of the sensorimotor system [65]. They found that after 24 hours of left-hand immobilization sensorimotor representation of the immobilized hand was altered, and that 48 hours later, representations of both immobilized and non-immobilized hands were impaired $[59,74]$. Moreover, they also demonstrated that upper limb immobilization for 48 hours did not impact upon sensorimotor representation of lower limbs [58].

Bidet-Ildei et al. [5] found that 24 hour immobilization of the right hand can affect action verb processing. Using a semantic decision task in which individuals had to judge whether an action verb involved hand or foot movements, they observed that control participants whose hands were not restricted responded more quickly to hand action verbs than to foot action verbs in pre- and post-tests. Conversely, after immobilization, participants did not display significant difference in response time between hand and foot action verb processing even though, like their control counterparts, they had responded more quickly to hand action verbs in the pre-test. The lack of difference observed in immobilized subjects was interpreted by a lesser improvement in hand action verb processing between the pre- and post-tests, due to sensorimotor deprivation. These findings highlight that 
higher cognitive functions are closely associated with sensorimotor experience; this is fully in line with Lyons et al. [55], who compared expert players in ice-hockey to novices and found greater activation within left premotor cortex in experts listening to sentences related to specific hockey actions, while no such difference was registered when listing to sentences based on activities of daily living.

\section{Transient sensorimotor deprivation affects brain organization}

To study the effects of transient sensorimotor deprivation on human brain organization, two main groups of subjects have been studied: healthy individuals deprived of afferent and efferent information by wearing a cast or a splint $[1,45,76]$; and individuals suffering from orthopedic trauma injuries requiring a cast or splint on the injured body part $[53,54]$.

Imposing temporary upper limb immobilization on healthy participants, Huber et al. [45] found, after 12 consecutive hours of immobilization, changes in the contralateral sensorimotor cortex indicating motor performance deterioration and depression of somatosensory and motor evoked potentials for the immobilized upper limb.

Along similar lines, after 10 hours of immobilization of the right hand, Avanzino et al. [1] found decreased cortical excitability within left primary motor cortex (M1) as well as diminution of inter-hemispheric inhibition from left to right hemisphere. Interestingly, right hand immobilization led to increased excitability of right primary motor cortex as well as greater inter-hemispheric inhibition from right to left hemisphere, only observed among subjects who used their left arm excessively. This increased excitability could be due to increased proprioceptive input generated by overuse of the left hand. Using fMRI, after 72 hours of immobilization of the right hand and forearm, Weibull et al. [76] showed decreased activation in ipsilateral primary somatosensory cortex and primary motor cortex when performing a finger-tapping task with the immobilized hand. Conversely, performing the same task with the nonimmobilized hand was associated with bilateral increased activation within primary somatosensory, primary motor and sensory association cortex. This study also revealed loss of grip strength, dexterity and tactile discrimination of the immobilized hand associated with increased tactile discrimination of the non-immobilized hand.

In individuals suffering from orthopedic trauma injuries, Lissek et al. [54] showed, after a six week immobilization period of hand and arm, impairment in tactile perception, hand use and shrinkage of somatosensory cortical maps. Perceptual compensation also occurred, reflected by enhanced tactile acuity in the non-affected hand. Langer et al. [53] described reduced cortical thickness within the contralateral sensorimotor cortex as well as fractional anisotropy (FA) decrease in the contralateral corticospinal tract after two weeks' immobilization of the whole right arm. Moreover, observed increases in cortical thickness within right primary motor cortex and FA within right premotor cortex were interpreted as compensatory processes.

Taken altogether, transient sensory and motor deprivation, investigated by means of upper limb immobilization, lead to rapid remodeling of the sensorimotor system reflected by functional as well as structural changes. Decreased activation in sensorimotor cortex and deterioration of motor performance were observed $[1,45,53,54,76]$. Compensation effects reflected by substantial activation increases in adjacent or contralateral areas of the immobilized upper limb have also been observed, suggesting compensation for areas that are deprived of input. This has been explained by increased use of the non-immobilized hand to deal with daily demands $[1,53,54,76]$.

\section{Does transient sensorimotor deprivation affect motor simulation?}

To investigate whether sensorimotor deprivation affects motor simulation processes, studies looked at either healthy individuals deprived of sensorimotor information [11] or individuals with orthopedic trauma injuries [12]. Asking healthy participants to wear a splint on the right hand, Burianova et al. [11] observed, after 24 hours of immobilization, changes in brain activity when the subjects performed the finger configuration task, which requires implicit use of motor imagery [10]. They found a resting motor threshold increase in motor cortex contralateral but not ipsilateral to the immobilized hand, suggesting decreased corticospinal excitability in projections to the immobilized hand. Activation decrease within primary motor cortex and BA6 contralateral to the immobilized hand were also detected. Curiously, imagery performances assessed by the finger configuration task did not change after immobilization, regardless of laterality of hand immobilization.

In Calmels et al. [12], brain hemodynamic activity was recorded twice in 13 national female gymnasts suffering from a lower extremity injury at the onset of the experiment. The gymnasts were scanned one month after the injury and were shown gymnastic routines they were normally able but temporarily unable to perform. Six months later, after complete recovery, they were scanned again and shown the same routines that by this time they were able to practice again. Results showed firstly that activity within inferior parietal lobule and MT/V5/EBA (extrastriate body area), areas constitutive of the action observation network, was independent of the gymnasts' physical condition. Second, during the period of injury, higher activity in cerebellum was detected. The equal contribution of MT/V5/EBA and inferior parietal lobule during the observation of movements that the gymnasts were able or unable to practice suggests respectively that physical provisional incapacity does not interfere with perceptual processing of body shape and motion information, and that motor expertise may prevent the deterioration of sensorimotor representations. Higher activations occurred in cerebellum, which is known to play a key role in prediction of sensory consequences $[6,78]$ and updating predictions about visual consequences of behavior [72]. This suggests that when injured, predicting the outcome of others' viewed actions may be affected. As a consequence, estimated error between predicted outcomes and incoming consequences of the viewed movement may be higher.

Taken together, both types of study show that transient sensorimotor deprivation affects brain organization during 
motor simulation. However, additional studies are required to better elucidate this issue.

\section{Training the brain to counteract detrimental effects of transient sensorimotor deprivation}

It is therefore reasonable to consider the possibility of preventing deterioration of motor representations or even their loss, in subjects with transient sensory and motor deprivation. Is it possible to generate sensations, such as kinesthetic and haptic sensations, without concomitantly performing actual movements? Can motor simulation allow this?

Individual experiential testimonies indicate that subjects performing motor simulation, are able to experience sensations. This can be explained: first, kinesthetic sensations perceived during motor imagery must be the result of expected sensory consequences of the action, as they are not generated by actual movement nor by peripheral input $[29,33,48,63]$. Second, when observing others' actions, motor and somatosensory cortices of the observer are activated as if the observer was really performing the viewed action $[15,31,51]$. The observer thus simulates motor output and somatosensory input necessary to produce the viewed action [51]. Interestingly, primary somatosensory area BA2 is not limited to encoding somatosensory information as was long believed, but is also involved in motor information coding [75]. Moreover, Calvo-Merino et al. $[13,14]$ showed that activation of this area when observing classical dance movements was positively correlated to the observer's degree of motor expertise. Finally, Guillot et al. [35] demonstrated that combining motor simulation (and more specifically imagery) with mimes increased vividness of imagery, temporal congruence between imagery and actual execution and technical quality and efficacy of movements. Thus, coupling mimed actions involving hands, upper body or whole body with motor simulation (i.e., imaged, observed, verbalized actions) could induce peripheral sensations. These sensations could be more intense than those elicited by motor simulation alone but less than those generated by actual execution of movements.

To summarize, since many common cortical areas are activated both during motor simulation and execution of movements, and since motor simulation can produce peripheral sensations needed to drive brain plasticity for cortical reorganization, it could thus be postulated that practicing motor simulation constitutes training for actual execution of movements. Consequently, motor simulation could be a means to counteract negative effects of transient sensorimotor deprivation.

Few studies have investigated this topic in subjects with no past neurological history, who experience an immobilization period due to a traumatic limb injury $[56,61]$ or in whom such immobilization is imposed for experimental reasons [4,19,57]. First, both Moukarzel et al. [61] and Marusic et al. [56] found some benefits of using motor simulation in rehabilitation of patients who had respectively undergone total knee and hip arthroplasty surgery. More specifically, Moukarzel et al. [61] instructed patients to perform visual imagery from an internal and external perspective as well as kinesthetic imagery. Three 15 minute-sessions per week were provided for 4 weeks and three sets of imagery programs were devised based on the intended goals:

- pain management;

- knee flexion range of motion increase;

- quadriceps strength improvement.

Moukarzel et al. [61] mainly showed decreased pain and increased quadriceps strength. Marusic et al. [56] asked patients to observe video clips depicting locomotor actions and concomitantly to feel the sensations as if they were actually performing the action. Twenty-six sessions, each lasting 30 minutes and spread over 2 months, were performed. Results showed better motor performances in patients following the motor simulation program compared to control patients who did not benefit from this program. However, no difference was observed when performing motor actions outside the motor simulation training program.

Second, studies of healthy participants wearing a cast or a splint to induce temporary sensorimotor deprivation show divergent results $[4,19,57]$. Using an experimental pretest/post-test design with control and experimental groups, Crews and Kamen [19] placed all subjects' left hands in a cast during a period of seven days. The experimental group followed an imagery program composed of 300 trials in which a motor task devised by Payton et al. [67], requiring abduction movements of the little finger, had to be mentally performed. Subjects were asked to imagine themselves performing the task from an internal perspective and to feel kinesthetic sensations associated with this task. Three 30-minute training sessions were spread over the immobilization period. The control group did not follow the imagery program. After the cast had been removed, Crews and Kamen [19] found, decrease in motor evoked potential within the hand area of the primary motor cortex in both groups with no difference between these. As for motor performances of the task imaged by the experimental group, there were no differences in accuracy scores, but error scores were higher in the experimental group. Crews and Kamen thus [19] showed that motor imagery failed to counteract the detrimental effects of transient sensorimotor deprivation.

Bassolino et al. [4] immobilized the right arm of all subjects for 10 hours and used an experimental pretest/post-test design with three groups (control group, observation group, and imagery group). The control group watched documentaries with no human agents whereas the observation group observed videos displaying a right hand from an internal perspective, reaching and grasping objects with different kinds of grips. The imagery group was instructed to imagine, with eyes closed, reaching and grasping objects with their immobilized hand while trying to feel the sensations they experienced when actually performing the action. Tasks described above were performed ten times at the rate of one session per hour, each session lasting around 4 minutes. Bassolino et al. [4] found that only observation was able to counteract the negative effects of sensorimotor deprivation, as motor cortex excitability registered in the observation group was greater than that recorded in control and imagery groups. 
Meugnot et al. [57] recruited participants who were randomly assigned to four groups:

- immobilized group practicing visual imagery;

- immobilized group practicing kinesthetic imagery;

- immobilized group with no imagery practice, and;

- non-immobilized group with no imagery practice.

Immobilized participants wore a splint on their left hand for 24 hours. In visual imagery, subjects were instructed to imagine themselves performing hand and finger motor actions with their immobilized hand by focusing on visual information. In kinesthetic imagery, they were to feel themselves performing hand and finger motor actions with their immobilized hand by focusing on kinesthetic information. Imagery sessions were executed just before splint removal during 3 sequences of 5 minutes, with eyes closed. $A$ hand laterality task, recognized to provide information on the central processing of the sensorimotor system [65], was completed by all participants just after the splint removal. Meugnot et al. [59] found that only kinesthetic imagery was able to counteract the negative effects induced by transient sensorimotor deprivation, reflected by slowing of sensorimotor processes.

In view of these results, the benefits of using motor simulation to prevent detrimental effects of transient sensorimotor deprivation have been highlighted by some researchers, whereas others take the opposite view. To account for these divergent results, three explanations are suggested.

First, divergences could be attributed to recruitment: transient sensorimotor deprivation induced by immobilization because of trauma, or that artificially reproduced for experimental reasons, might not produce similar effects on brain plasticity. Second, duration of immobilization may play a role, since different mechanisms occur depending on whether immobilization is brief (i.e., 24 hours) or longer (i.e., a week, a month or even several months). Third, as shown by Isaac [46], the efficacy of motor imagery training depends on individual's imagery ability: subjects with poor imagery ability could find it difficult to apply and follow instructions provided by the experimenters. In the five reviewed studies, 3 assessed the imagery ability of the participants and those with poor imagery ability were either not included in the study or were trained to enhance their ability $[4,19,61]$.

In conclusion, though some divergent results are observed, using motor simulation in addition to traditional physical rehabilitation appears of interest, potentially allowing individuals with transient sensorimotor deprivation to optimize recovery and safe return to daily life activities. However, more clinical research in the field of orthopedic trauma is necessary in order to optimize the impact of motor simulation.

\section{Applied perspectives}

For motor imagery, principles as described by the Physical, Environment, Task, Timing, Learning, Emotion, Perspective (PETTLEP) [43] or MIMS (the Integrated Motor Imagery Model applied to Sports) [34] model could be helpful. Thus, the practitioner should be aware of what an imagined action consists of and how the subject imagines it, in order to design a tailor-made program for each subject:

- image generation (i.e. does the individual imagine an action with open or closed eyes?);

- posture of the imager (i.e. is the individual lying down, sitting or standing?);

- visual perspective and viewing angle (i.e. does the imager use an internal or external, or a combination visual perspective, and which viewing angle is favored?);

- imaging modalities (i.e. which senses are involved during mental imaging? Visual modality? Kinesthetic? Auditory? Olfactive? Tasting? A combination?);

- imaging speed (i.e. are the temporal characteristics of the performed move reflected by the imaged move? Does the imager create the move at the same speed as that of actual performance, or is the imaged move faster, or slower?);

- agency (i.e. do imagers picture themselves, or another, or an avatar?);

- including physiological and emotional elements to imagery (i.e. should practitioners feature emotional content [fear, frustration, enthusiasm] and/or physiological responses [tremors, muscular tension, fatigue, sweaty palms]?).

Likewise, in order to increase the efficiency of observation, users must follow a number of principles derived from sport psychology and neuroscience findings [41,42]. Users will make decisions based on these results and on each specific situation and include these elements to observation sessions. For example:

- observation content (i.e. is it better to observe a model during the learning phase, performing correct executions, or performing with mistakes?);

- visual perspective and viewing angle (i.e. is it more beneficial to observe a model from an internal or external perspective? And, in the case of an external perspective, from which viewing angle? Should the model face the observer, or should they be watched from behind?);

- nature of instructions provided prior to an observation session (i.e. observe a movement, no instruction provided? Observe a move aiming to replicate it later on? Observe a move in order to image/mime it later? Combining observation of a move and concomitant mimes?);

- agency (i.e. is the observer watching his own performance or that of another?);

- expertise level of the observed model (i.e. does the model possess the same level of motor expertise as the observer? Is their level lower or higher?);

- observation context (i.e. should the context be defined or not? If context is specified, should it feature a stake?).

In order to maximize the efficacy of the movement verbalization process, verbal sequences, action verbs and key words should be meaningful to the subject. Thus, the subject is encouraged to generate, with the practitioner's help, their own verbalizations, which may evolve with time.

Lastly, regarding a mimed task which generates peripheral sensations, a number of questions emerge: should the 
subject mime the entire movement, or only parts? Should mimed sequences be performed using hands, upper or lower half-body, or the whole body? Should an object related to activities of daily living be used, or not?

Thus, a personalized support program, based on motor simulation, is designed jointly with the injured subject. This program takes the subject's individuality into account, notably personal history, sensitivity and personal experience, not forgetting context. More specifically, choosing to use one simulation technique over another will depend on the individual's mental resources and their mastery, and the purpose and scope of motor simulation. For instance, these techniques can be used alone or in combination, with or without mimed sequences, e.g. movement imagery; movement imagery + movement verbalization; movement observation; or movement observation + mimed movement. Finally, efficacy depends heavily on the subject's voluntary participation; in the case of forced participation, optimal results are not to be expected [20]. Currently implemented with injured athletes on a national campus in France, this approach with motor simulation at its core has yielded promising results.

\section{Conclusion}

Associating motor simulation with more traditional physical rehabilitation is a promising avenue in sport and clinical settings. For example, in sports, motor simulation could help prevent injuries or allow athletes to maximize their movement potential either by removing erroneous movement patterns that prevent them from attaining excellence, or by creating new ones.

\section{Disclosure of interest}

The author declares that he has no competing interest.

\section{References}

[1] Avanzino L, Bassolino M, Pozzo T, Bove M. Use-dependent hemispheric balance. J Neurosci 2011;31:3423-8.

[2] Aziz-Zadeh L, Wilson SM, Rizzolatti G, lacoboni M. Congruent embodied representations for visually presented actions and linguistic phrases describing actions. Curr Biol 2006;16:1818-23.

[3] Bassolino M, Bove M, Jacono M, Fadiga L, Pozzo T. Functional effect of short-term immobilization: kinematic changes and recovery on reaching-to-grasp. Neuroscience 2012;215:127-34.

[4] Bassolino M, Campanella M, Bove M, Pozzo T, Fadiga L. Training the motor cortex by observing the actions of others during immobilization. Cereb Cortex 2014;24:3268-76.

[5] Bidet-Ildei C, Meugnot A, Beauprez SA, Gimenes M, Toussaint L. Short-term upper limb immobilization affects action-word understanding. J Exp Psychol Learn 2017;43:1129-39.

[6] Blakemore SJ, Frith CD, Wolpert DM. The cerebellum is involved in predicting the sensory consequences of action. Neuroreport 2001;12:1879-84.

[7] Block H, Bastian A, Celnik P. Virtual lesion of angular gyrus disrupts the relationship between visuoproprioceptive weighting and realignment. J Cogn Neurosci 2013;25:636-48.
[8] Borich MR, Brodie SM, Gray WA, Ionta S, Boyd LA. Understanding the role of the primary somatosensory cortex: opportunities for rehabilitation. Neuropsychologia 2015;79:246-55.

[9] Bosbach S, Cole J, Prinz W, Knoblich G. Inferring another's expectation from action: the role of peripheral sensation. Nat Neurosci 2005;8:1295-7.

[10] Burianova H, Marstaller L, Sowman P, Tesan G, Rich AN, Williams $M$, et al. Multimodal functional imaging of motor imagery using a novel paradigm. Neuroimage 2013;71:50-8.

[11] Burianova H, Sowman PF, Marstaller L, Rich AN, Williams MA, Savage G, et al. Adaptive motor imagery: a multimodal study of immobilization-induced brain plasticity. Cereb Cortex 2016;26:1072-80.

[12] Calmels C, Pichon S, Grezes J. Can we simulate an action that we temporarily cannot perform? Neurophysiol Clin 2014;44:433-45.

[13] Calvo-Merino B, Glaser DE, Grèzes J, Passingham RE, Haggard P. Action observation and acquired motor skills: an fMRI study with expert dancers. Cereb Cortex 2005;15:1243-9.

[14] Calvo-Merino B, Grèzes J, Glaser DE, Passingham RE, Haggard P. Seeing or doing? Influence of visual and motor familiarity in action observation. Curr Biol 2006;16:1905-10.

[15] Caspers S, Zilles K, Laird A, Eickhoff SB. ALE meta-analysis of action observation and imitation in the human brain. Neuroimage 2010;50:1148-67.

[16] Chen SX, Kim AN, Peters AJ, Komiyama T. Subtype-specific plasticity of inhibitory circuits in motor cortex during motor learning. Nat Neurosci 2015;18:1109-15.

[17] Cichon J, Gan WB. Branch-specific dendritic $\mathrm{Ca}(2+)$ spikes cause persistent synaptic plasticity. Nature 2015;520:180-5.

[18] Cohen LG, Celnik P, Pascual-Leone P, Corwell B, Falz L, Dambrosia J, et al. Functional relevance of cross-modal plasticity in blind human. Nature 1997;389:180-3.

[19] Crews RT, Kamen G. Motor-evoked potentials following imagery and limb disuse. Int J Neuroscience 2006;116:639-51.

[20] Daly JM, Brewer BW, Van Raalte JL, Petitpas AJ, Sklar JH. Emotional adjustement et adherence to rehabilitation following a knee surgery. J Sport Rehabil 1995;4:23-30.

[21] Davare M, Montague K, Olivier E, Rothwell JC, Lemon RN. Ventral premotor to primary motor cortical interactions during object-driven grasp in humans. Cortex 2009;45:1050-7.

[22] Desmurget M, Sirigu A. A parietal-premotor network for movement intention and motor awareness. Trends Cogn Sci 2009;13:411-9.

[23] Desmurget M, Reilly KT, Richard N, Szathmari A, Mottolese C, Sirigu A. Movement intention after parietal cortex stimulation in humans. Science 2009;324:811-3.

[24] Elbert T, Pantev C, Wienbruch C, Rockstroh B, Taub E. Increased cortical representation of the fingers of the left hand in string players. Science 1995;270:305-7.

[25] Elias JW, Wagster MV. Developing context and background underlying cognitive intervention/training studies in older populations. J Gerontol B Psychol Sci Soc Sci 2007;62S1:5-10.

[26] Espinosa JS, Stryker MP. Development and plasticity of the primary visual cortex. Neuron 2012;75:230-49.

[27] Flor $\mathrm{H}$, Elbert $\mathrm{T}$, Knecht S, Wienbruch C, Pantev C, Birbaumer N, et al. Phantom-limb pain as a perceptual correlate of cortical reorganization following arm amputation. Nature 1995;375:482-4.

[28] Flor H, Nikolajsen L, Jensen TS. Phantom limb pain: a case of maladaptive CNS plasticity? Nat Rev Neurosci 2006;7:873-81.

[29] Frith C, Dolan RJ. Brain mechanisms associated with top-down processes in perception. Philos T Roy Soc B 1997;352:1221-30.

[30] Furlan L, Conforto AB, Cohen LG, Sterr A. Upper immobilization: a neural plasticity model with relevance to poststroke motor rehabilitation. Neural Plast 2016;2016:8176217.

[31] Gazzola V, Keysers C. The observation and execution of actions share motor and somatosensory voxels in all tested subjects: 
single-subject analyses of unsmoothed fMRI data. Cereb Cortex 2009;13:1239-55.

[32] Grezes J, Decety J. Functional anatomy of execution, mental simulation, observation and verb generation of action. Hum Brain Mapp 2001;12:1-19.

[33] Grush R. The emulation theory of representation: motor control, imagery, and perception. Behav Brain Sci 2004;27: 377-96.

[34] Guillot A, Collet C. Construction of the motor imagery integrative model in sport: a review and theoretical investigation of motor imagery use. Int Rev Sport Exer 2008;1:31-44.

[35] Guillot A, Moschberger K, Collet C. Coupling movement with imagery as a new perspective for motor imagery practice. Behav Brain Funct 2013;9:8.

[36] Hardwick RM, Caspers S, Eickhoff SB, Swinnen SP. Neural correlates of action: comparing meta-analyses of imagery, observation, and execution. Neurosci Biobehav Rev 2018;94: 31-44.

[37] Hauk O, Johnsrude I, Pulvermuller F. Somatotopic representation of action words in human motor and premotor cortex. Neuron 2004;41:301-7.

[38] Hayashi-Takagi A, Yagishita S, Nakamura M, Shirai F, Wu Yi I, Loshbaugh AL, et al. Labelling and optical erasure of synaptic memory traces in the motor cortex. Nature 2015;525: 333-8.

[39] Hetu S, Gregoire M, Saimpont A, Coll MP, Eugene F, Michon $\mathrm{PE}$, et al. The neural network of motor imagery: an ALE metaanalysis. Neurosci Biobehav Rev 2013;37:930-49.

[40] Hoffstaedter F, Grefkes C, Zilles K, Eickhoff SB. The "What" and "When" of self-initiated movements. Cereb Cortex 2013;23:520-30.

[41] Holmes P, Calmels C. A neuroscientific review of imagery and observation use in sport. J Motor Behav 2008;40:433-45.

[42] Holmes P, Calmels C. Mental practice: neuroscientific support for a new approach. In: Collins D, Abbott A, Richards H, editors. Performance psychology for physical challenge. London: Elsevier; 2011. p. 231-44.

[43] Holmes PS, Collins DJ. The PETTLEP approach to motor imagery: a functional equivalence model for sport psychologists. J Appl Sport Psychol 2011;13:60-83.

[44] Hoshi E, Tanji J. Distinctions between dorsal and ventral premotor areas: anatomical connectivity and functional properties. Curr Opin Neurobiol 2007;17:234-42.

[45] Huber R, Ghilardi MF, Massimini M, Ferrarelli F, Riedner BA, Peterson MJ, et al. Arm immobilization causes cortical plastic changes and locally decreases sleep slow wave activity. Nat Neurosci 2006;9:1169-76.

[46] Isaac AR. Mental practice-does it work in the field? Sport Psychol 1992;6:192-8.

[47] Jeannerod $M$. The representing brain: neural correlates of motor intention and imagery. Behav Brain Sci 1994; 17:182-202.

[48] Jeannerod M. Neural simulation of action: a unifying mechanism for motor cognition. Neurolmage 2001;14:S103-9.

[49] Jeannerod M. Motor cognition: what actions tell the self. Oxford: Oxford University Press; 2006.

[50] Kawato M. Internal models for models for motor control and trajectory planning. Curr Opin Neurobiol 1999;9:718-27.

[51] Keysers C, Kaas JH, Gazzola V. Somatosensation in social perception. Nat Rev Neurosci 2010;11:417-28.

[52] Ko M, An J, Bandukwala HS, Chavez L, Aijo T, Pastor WA, et al. Modulation of TET2 expression and 5-methylcytosine oxidation by the CXXC domain protein IDAX. Nature 2013;497: 122-6.

[53] Langer N, Hanggi J, Muller NA, Simmen HP, Jancke L. Effects of immobilization on brain plasticity. Neurology 2012;78: $182-8$.
[54] Lissek S, Wilimzig C, Stude P, Pleger B, Kalisch T, Maier C, et al. Immobilization impairs tactile perception and shrinks somatosensory cortical maps. Curr Biol 2009;19:837-42.

[55] Lyons IM, Mattarella-Micke A, Cieslak M, Nusbaum HC, Small $\mathrm{SL}$, Beilock SL. The role of personal experience in the neural processing of action-related language. Brain Lang 2010;112:214-22.

[56] Marusic U, Grosprêtre S, Paravlic A, Kovac S, Pisot R, Taube W. Motor imagery during action observation of locomotor tasks improves rehabilitation outcome in older adults after total hip arthroplasty. Neural Plast 2018;2018:5651391.

[57] Meugnot A, Agbangla NF, Almecija Y, Toussaint L. Motor imagery practice may compensate for the slowdown of sensorimotor processes induced by short-term upper-limb immobilization. Psychol Res 2015;79:489-99.

[58] Meugnot A, Agbangla NF, Toussaint L. Selective impairment of sensorimotor representations following short-term upper-limb immobilization. Q J Exp Psychol 2016;69:1842-50.

[59] Meugnot A, Toussaint L. Functional plasticity of sensorimotor representations following short-term immobilization of the dominant versus non-dominant hands. Acta Psychol 2015;155:51-6.

[60] Moisello C, Bove M, Huber R, Abbruzzese G, Battaglia F, Tononi $G$, et al. Short-term limb immobilization affects motor performance. J Motor Behav 2008;40:165-76.

[61] Moukarzel M, Di Rienzo F, Lahoud JC, Hoyek F, Collet C, Guillot $A$, et al. The therapeutic role of motor imagery during the acute phase after total knee arthroplasty: a pilot study. Disabil Rehabil 2017;24:1-8.

[62] Nachev P, Kennard C, Husain M. Functional role of the supplementary and pre-supplementary motor areas. Nat Rev Neurosci 2008;9:856-69.

[63] Naito E, Kochiyama T, Kitada R, Nakamura S, Matsumura M, Yonekura $Y$, et al. Internally simulated movement sensations during motor imagery activate cortical motor areas and the cerebellum. J Neurosci 2002;22:3683-91.

[64] Olson CR, Colby CL. Spatial cognition. In: Squire L, Berg D, Bloom FE, Lac S, Ghosh A, Spitze NC, editors. Fundamental neuroscience. 4th edition London: Elsevier; 2013. p. 969-88.

[65] Parsons LM. Temporal and kinematic properties of motor behavioural reflected in mentally simulated action. J Exp Psychol Human 1994;20:709-30.

[66] Pascual-Leone A, Amedi A, Fregni F, Merabet LB. The plastic human brain cortex. Ann Rev Neurosci 2005;28:377-401.

[67] Payton OD, Su S, Meydrech EF. Abductor digiti quinti shuffleboard: a study in motor learning. Arch Phys Med Rehab 1976;57:169-74.

[68] Peran P, Demonet JF, Cherubini A, Carbebat D, Caltagirone C, Sabatini U. Mental representations of action: the neural correlates of the verbal and motor components. Brain Res 2010;1328:89-103.

[69] Rushworth MF, Nixon PD, Wade DT, Renowden S, Passingham RE. The left hemisphere and the selection of learned actions. Neuropsychologia 1998;36:11-24.

[70] Sirigu A, Duhamel JR, Cohen L, Pillon B, Dubois B, Agid Y. The mental representation of hand movements after parietal cortex damage. Science 1996;273:1564-8.

[71] Sterr A, Muller MM, Elbert T, Rockstroh B, Pantev C, Taub E. Changed perceptions in Braille readers. Nature 1998;391:134-5.

[72] Synofzik M, Lindner A, Their P. The cerebellum updates predictions about the visual consequences of one's behavior. Curr Biol 2008;18:814-8.

[73] Toni I, Thoenissen D, Zilles K. Movement preparation and motor intention. Neuroimage 2001;14:S110-7.

[74] Toussaint L, Meugnot A. Short-limb immobilization affects cognitive motor process. J Exp Psychol Learn 2013;39:623-32. 
[75] Valchev N, Gazzola V, Avenanti A, Keysers C. Primary somatosensory contribution to action observation brain activity-combining fMRI and CTBS. SCAN 2016;11:1205-17.

[76] Weibull A, Flondell M, Rosen B, Bjorkman A. Cerebral and clinical effects of short-term hand immobilisation. Eur J Neurosci 2011;33:699-704.
[77] Wise SP, Murray EA. Arbitrary associations between antecedents and actions. Trends Neurosci 2000;23:271-6.

[78] Wolpert DM, Miall RC, Kawato M. Internal models in the cerebellum. Trends Cogn Sci 1998;2:338-47. 